[Deutsche Entomologische Zeitschrift XXVII. 1883. Heft II.]

\title{
Relazione di un viaggio nelle Calabrie fatto 1876 pel A. Costa.
}

Besprochen von

Dr. L. $v$ o $n$ Heyden.

In den Atti della R. academia delle Scienze di Napoli 1882. Vol. IX. No. 4. giebt Achille Costa unter dem Titel "Rel. di un viag. nelle Calabrie per ricerche zoologische fatto nella state del $1876^{\text {" }}$ Bericht über eine naturwissenschaftliche Reise nach Calabrien. Da diese Zeitschrift wohl in den Händen weniger Entomologen sein wird, jedoch eine Anzahl Beschreibungen neuer Arten mit Abbildungen enthält, so gebe ich hier das Hauptsächlichste im Auszuge.

p. 1-32. Reisebericht über Calabria ulteriore und Sila-Gebirg. (Sila grande und Sila piccola seither als Brigantennester verrufen und daher wissenschaftlich fast unbekannt.)

p. 33. Descrizione di specie nuove.... und zwar: Coleotteri: Brachinus bisigniferus Costa, Fig. 1. Rufo-testaceus, elytris acute costulatis, cyaneo-virescentibus, macula postica subrotunda testacea; abdomine obscuro. Long. $7 \frac{1}{2}$ mill., lat. max. $3 \frac{1}{3}$ mill. ${ }^{1}$ ). Adiacenze di Cirò l. d. "le vurghe", sotto tronchi di vecchi Tamarisci prostrati al suolo; aprile, un solo individuo. - Mit B. Bayardi Dej. verwandt, aber viel grölser, Decken breiter und flacher.

p. 33. fig. 2. Ophonus zigzag Costa. Oblongus, supra obscure piceus, elytris saturatioribus, subtus cum ore antennisque rufo-piceus; parce pubescens, capite crebre confertim punctato, pronoto posterius modice angustato, parum convexo, crebre et confertim punctato, sulco medio longitudinali distincto, ac in disco lineolis transversis biangulatis parallelis impressis notato. Long. 7 mill. Sila grande: rarissimo. - Mit $O$. brevicollis Dej. verglichen.

p. 34. fig. 3. Elater coenobita Costa. Ater, nitidus, nigropubescens; pronoto crebre punctato, per totam longitudinem canaliculato, canaliculo basim versus latiore et profundiore; elytris lividoflavidis, sutura pallide ferruginea. Long. 14 mill. - Boschi di

1) Die jedesmal folgende italienische Beschreibung übergehe ich. 
Serra S. Bruno, sotto le cortecce dei faggi; tre individui. - Mit E. sanguineus verwandt, aber durch anderes Halsschild und schmale gelbe Decken verschieden.

p. 34. fig. 4 (ㅇ). Lampyris brutia Costa. 우 elytris basi latis, dein introrsum oblique sinuato-angustatis, apice valde angustato abdominis segmenti primi dimidium attingentibus; scutello postice truncato rotundato, prosterno antice truncato; pygidio postice rotundato. Long. 14-16 mill. - $\sigma^{\top}$ pygidio postice rotundato, segmento ventrali septimo margine postico leviter arcuato-emarginato. Long. 10-11 mill. - Adiacenze di Cirò luglio, abondantissima. Raccolta pure in San Giovanninferiore. - Mit L. Reichei durch die Form der weiblichen Flügeldecken verwandt, gehört sie nach der Form des männliches Analsegmentes in die Gruppe der L. Lareynii.

p. 35. fig. 5. Haplocnemus variolatus Costa. Aeneus, dense cinereo-flavescente pilosus, antennis, palpis pedibusque fulvis; elytris limbo postico indeterminante rufescente; pronoto subtiliter, elytris grosse et profunde discrete punctatis. Long. 4 mill. - Sila piccola, sopra i fiori de' cardi, adiacenze di Giovanninferiore. Mit calidus verwandt, aber Fühler und Beine anders gefärbt; auch mit limbipennis $\mathrm{Ksw}$. verwandt, aber auch schon durch die Gröfse von beiden verschieden.

p. 35. Cantharis crassicornis Costa. Viridi-purpurascens, antennis crassioribus omnino nigris; sculptura ut in C. vesicatoria. Long. 17 mill. - Ivi : aprile: un solo individuo. - Mit C. vesicatoria L. verwandt, aber die 2 oder 3 ersten Fühlerglieder ganz schwarz, nicht metallisch; die Fühler sind kürzer und dicker vom dritten Glied an; auch die Jahreszeit April sei verschieden, wie bei der im Juni erscheinenden $L$. vesicat.

p. 36. fig. 6. Ancylopus testaceus Costa. Pallide testaceus, unicolor, crebre punctatus, brevissime pubescens; pronoto transverso, ante medium angulato-dilatato; tibiis anticis parum ultra medium spina armatis. Long. 4 mill. - Adiacenze di Cirò (carafone di S. Nicola) luglio, assai raro. - Steht sehr nahe dem A. unicolor Gerst. von Port-Natal.

\section{Ortotteri.}

p. 36. fig. 7. Forficula (Apterygia) apennina Costa. Corpore angustato subparallelo, obscure piceo, capite piceo-rufescente, pronoto elytrisque griseo-testaceis. Mas: lamina anali crassa, angustata, margine postico subtruncato, triapiculato; forcipe fere abdominis longitudine, cruribus pone busim et in medio dentatis; 
foemina: forcipe valde breviore, cruribus subrectis, ad apicem modice intus incurvatis ac se decussantibus. Long. corp. 10-12 mill., forc. $\sigma^{\top} 6-8$ mill., $+3-4$ mill. - Sila grande e piccola, non rara. - Mit F. pedestris verwandt.

p. 37. fig. 8. Forficula (Apteroygia) silana Costa. Rufoferruginea vel picea, capite rufo-testaceo; pronoti lateribus pallidis pellucidis; abdominis segmento dorsali tertio utrinque plicato, ultimo medio impresso, postice bituberculato, plicis lateralibus elevatis crassis dilatato-angulatis; lamina anali brevissima, transversa, posterius profunde emarginato-lunata; forcipis cruribus in $\sigma^{\top}$ abdomine esiccato paulo brevioribus, basi latis intus $3-4$ dentatis, dein modice arcuatis, dente valido ad tertium longitudinis praeditis; in paulo brevioribus, apice intus incurvatis ac decussatis. Long. corp. 8-9 mill.; forc. ơ 4-5 mill., ㅇ 3 mill. - Sila grande; von rara. - Mit $\boldsymbol{F}$. auricularia verwandt.

p. 38. fig. 9. Forficula (Apteroygia) laminigera Costa. Crebre punctata, picea, pronoti lateribus, elytris pedibusque pallidis; abdominis segmentis secundo et tertio plicis lateralibus distinctis; forcipe abdominis dimidio breviore, cruribus validis, subtriquetris, rectis, apice tantum intus incurvatis; lamina anali inter forcipem porrecta, assurgente, subquadrata, postice truncato-emarginata, angulis prominulis. $\widetilde{\sigma}$. Long. corp. 10 mill., forc. $2 \frac{1}{2}$ mill. - Falde della Sila piccola, rara. - Mit der spanischen $F$. analis Ramb. verwandt.

\section{I $m$ e n o t $t$ er $i$.}

p. 39. fig. 11. Priocnemis ophthalmicus Costa. - Niger, antennis pedibusque rufo-fulvis, macula utrinque occipitali rufo-ferruginea, alis luteis, apice fumatis subviolascentibus; posticis cellula anali ante originem venae cubitalis terminata; metanoto postice transversim elevato-striato et subruguloso. ㅇ. Long. corp. 15 mill. - Adiacenze di Carfizzi. - Mit P. nigriventris verwandt.

p. 40. fig. 12. Pompilus rufithorax Costa. Niger, sericeonitens, abdominis segmentis margine postice cinerascente; thorace toto fulvo-rufo, mesopleuris tantum nigris; mandibulis ferrugineis, apice nigris; alis fumato-hyalinis, posticis cellula anali ante originem venae cubitalis terminata; metanoto laevi. ㅇ. Long. 7 mill. - Sila grande; assai raro. - Mit $P$. dimidiatus verwandt.

p. 40. Hoplocampa calceolata Costa. Nigra, nitida; femorum apice tibiisque maxima parte albidis; alis fumato-hyalinis, venis nigris, stigmate nigro-fusco. ㅇ. Long. 6 mill. - Sila grande, 
1. d. "Agarò", agosto, rara. - Wird mit Blennocampa cinereipes verglichen.

p. 40. Chalcis discrepans Costa. Antennis longis et gracilibus hypostomati insertis, scutello dentibus duobus erectis, femoribus mediis clavatis, posticis infra bidentatis; nigra nitida, argenteo pubescens, antennarum dimidio basali, tegulis alarum pedibusque totim laetis rufs. ㅇ. Long. 5 mill. - Adiacenze di Scandale, luglio; assai rara.

p. 41. Chalcis strigulosa Costa. Antennis gracilibus, prope clypeum insertis, canalicula frontali lata, parum profunda, transversim crebre striolata; scutello acute marginato, posterius laminari-producto, emarginato, bilobo; nigra, argenteo-pubescens, antennis basi piceis; tegulis alarum pedibusque rufo-ferrugineis, tibiis quatuor anterioribus in medio nigricantibus, tibiis tarsisque posticis nigris, femoribus posticis margine infero nigro, dentibus duobus triangularibus armato. ㅇ․ Long. 4 mill. - Adiacenze di Caccuri, luglio; assai rara.

\section{Lepidotteri.}

p. 41. fig. 13. Hemerophila serraria Costa. Pallide ochraceo-cinerascens, argenteo micans, sparse fusco punctata, alis margine externo grosse et obtuse dentatis; anticis fasciis duabus fuscis valde obliquis, latere interno a linea nigra valde sinuata cinctis, punctoque discoidali nigro costae magis quam margini postico approximato; fascia externa in alas posticas continuata. Latit. alis exp. 50-52 mill. - Adiacenze di Serra.

\section{Em it t e ri.}

p. 42. fig. 14. Macropterna foveicollis Costa. Antennarum articulo primo inflato, valido, capitis lobum medium non excedente: pronoti lobo antico valde convexo, levi; postico grosse punctato, sulco medio longitudinali pone lobum anticum in foveolam oblongam terminato; nigra, elytrorum corio albido, in parte externa postica nigro; membrana nigricante, fascia pone basim margineque apicali albidis; antennarum articulis secundo et tertio, tibiis tarsisque pallidis. Long. 2 mill. - Adiacenze di Cirò (Alice), sotto le cortecce di quercia; rarissima. - Mit M. marginalis Fieber verwandt.

p. 42-44 folgen Notizen über andere Arten.

p. 45-62. Elenco delle specie d'insetti raccolti .... hervorzuheben wäre, dafs der Longicorne Dorcatypus Fairmairei Thoms., sonst nur aus Griechenland bekannt, einmal auf dem Wege zwischen Cotrone und Scandale gefunden wurde. 


\section{$2 \mathrm{BHL}$ Biodiversity Heritage Library}

Heyden, Lucas von. 1883. "Relazione di un viaggio nelle Calabrie fatto 1876 pel A. Costa." Deutsche entomologische Zeitschrift 1883(2), 363-366. https://doi.org/10.1002/mmnd.48018830229.

View This Item Online: https://www.biodiversitylibrary.org/item/103692

DOI: https://doi.org/10.1002/mmnd.48018830229

Permalink: https://www.biodiversitylibrary.org/partpdf/235287

\section{Holding Institution}

Harvard University, Museum of Comparative Zoology, Ernst Mayr Library

\section{Sponsored by}

Harvard University, Museum of Comparative Zoology, Ernst Mayr Library

\section{Copyright \& Reuse}

Copyright Status: Public domain. The BHL considers that this work is no longer under copyright protection.

This document was created from content at the Biodiversity Heritage Library, the world's largest open access digital library for biodiversity literature and archives. Visit BHL at https://www.biodiversitylibrary.org. 